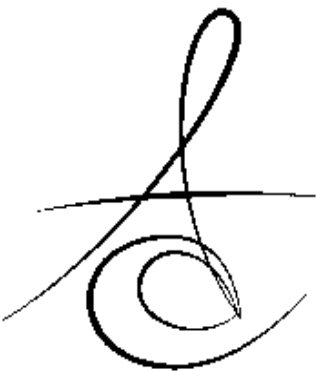

\title{
TOTAL PROTEZ OLGULARINDA SİSTEMİK HASTALIKLARIN ÖNEMİ
}

THE IMPORTANCE OF TOTAL PROSTHESIS IN PATIENTS WITH

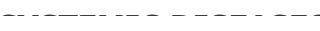

Prof. Dr. Zeynep YEŞİL DUYMUŞ*

Arş. Gör. Dt. Esra KUL**

Makale Kodu/Article code: 1109

Makale Gönderilme tarihi: 28.02.2013

Kabul Tarihi: 06.05.2013

\section{ÖZET}

Yaşı nüfus dünyada, özellikle gelişen ve gelişmekte olan ülkelerde artmaya devam etmektedir. Günümüzde bulaşıcı olmayan hastalıklar, sakatlıkların ve ölümlerin başlıca sebebi olmaya başlamıştır. Gelecek on yılda sağlık ve sosyal politikayı yönlendirenler, yaşla birlikte hızla artan sistemik hastalıklar yüzünden büyük problemlerle karşı karşıya kalacaklardır. Sistemik hastalıklar ve ağızda görülen bulguları önemlidir. Bu derlemede protetik açıdan önem arz eden sistemik hastalıklar ve bu hastalıklara sahip bireylere protez yaparken dikkat edilecek hususlar hakkında bilgi verilmiştir.

Anahtar Kelimeler: Sistemik hastalıklar, protez, dikkat edilecek hususlar.

\section{ABSTRACT}

Dentists are at risk in terms of pain, because of The elderly population continues to increase in the world, especially in developed and developing countries. Today, noninfectious diseases are becoming the leading cause of injuries and deaths. In the next decade, the people who now direct the health and social policies will be confronted with major problems due to systemic diseases rapidly increasing with age. Systemic diseases and their oral manifestations are important. This review provides information on systemic diseases that have significance in prosthodontics and points to be considered while making dentures in individuals with these diseases.

Keywords: Systemic diseases, dentures, points to be considered

\section{GİRİŞ}

Stomatognatik sistem; baş ve boyun çevresindeki kaslar, çiğneme kasları, ligamanlar, temporomandibular eklem (TME), diş, yanak, dudak ve tükürük bezlerinden oluşmaktadır. Stomatognatik sistem, sadece çiğneme sırasında değil, yutma, soluk alıp verme ve konuşma sırasında da sürekli çalışır. İnsan vücudu bir bütün olarak düşünülürse, sistemin herhangi bir yerindeki sorun yalnızca o bölgenin fonksiyonlarını etkilemekle kalmaz, sisteme ait diğer bölge ve fonksiyonları da zincirleme olarak etkiler. ${ }^{1}$ İşte bu düşünceler tam protezleri etkileyen sistemik hastalıkları gündeme getirir. ${ }^{2}$

Protez yaparken bir diş hekiminin karşılaşabileceği sistemik hastalıklar şöyle sıralanabilir: ${ }^{2-7}$

\section{HORMONAL VE METABOLİK HASTALIKLAR \\ Diabet}

Karbonhidrat, yağ ve protein metabolizmasındaki düzensizliğe bağlı oluşan hiperglisemi ile karakterize kronik metabolik bir hastalıktır. Hastaların büyük bir kısmında insüline bağlı olmayan Tip 2 diabet görülmektedir. Genellikle 40 yaşın üstündeki kişilerde görülür ve görülme sıklığı yaşla birlikte artar. $^{3}$ Çeşitli doku ve organları tutan bu hastalığın temel özelliği damarlarda bozulmalara yol açmasıdır. ${ }^{4}$

Hastada çizgili çatlak bir dil, ${ }^{5,6}$ anemik bir mukoza, madeni bir tat, ileri vakalarda ise ağızda aseton kokusu mevcuttur. Ağız mukozasının direnci düştüğünden, özellikle candida albicans'lar patojenite kazanır. ${ }^{5}$ Ağız kuruluğu oluşur, tükürüğün tamponlama

* Recep Tayyip Erdoğan Üniversitesi Diş Hekimliği Fakültesi Protetik Diş Tedavisi Ana Bilim Dal

** Atatürk Üniversitesi Diş Hekimliği Fakültesi Protetik Diş Tedavisi Ana Bilim Dalı 
kapasitesinin azalmasına ve total protezlerin yetersiz hijyenine bağlı olarak enfeksiyon riski artar. Ağızda yanma şikayeti (Burning mouth syndrome (BMS)), tam protez kaidesine karşı gelen mukozada ise erozyon ve ülserasyon görülür. ${ }^{7-9}$ Yara iyileşmesinde görülen gecik me ve alveoler kemikte oluşan fazla rezorbsiyon tam protezlerin yapımını ve kullanımını olumsuz yönde etkiler. $^{10}$

Diabetli hastalara protez yapılacağı zaman çok titiz davranılmalı, travmaya sebep olabilecek tüm etkenler ortadan kaldırımalı, tam protezlerde bilateral balans sağlanmalı, protez kenarları uzun olmamalı ve cilalı yüzeylere çok özen gösterilmelidir. Protezler geceleri kesinlikle çıkarılmalı, ağız dinlendirilmelidir. Bu hastalarda sıcak tuzlu su ile yapılan ağız gargaraları faydalı olmaktadır. Hastalar belirli aralıklarla mutlaka takip edilmeli, alveol kretlerinde rezorbsiyon oluştuğunda hemen astarlama yapılmalıdır.,

\section{Menopoz}

Hormonal ve psikolojik yönden ağır basan bir yaş dönemidir. Bu dönemin başlangıcında ağızda yanma hissi, ödem ve mukozanın kırmızılığı gibi bazı semptomlar görülebilir. ${ }^{11}$

Menopoz dönemindeki hastalara protez yapılacağı zaman çok anlayışı davranılmalı, protezin yapım tekniğine, özellikle estetiğine çok özen gösterilmelidir. ${ }^{2}$

\section{Osteoporoz}

Osteoporoz terimi genel olarak, mineralizasyonda defekt olmaksızın kemik kitlesindeki azalmayla karakterize bir grup hastalığı tanımlamak için kullanılır. Mutlak kemik kitlesindeki azalma belirlenmiş limitin altında ise iskeletsel osteopeni, iskeletsel kemik kitlesindeki azalmaya ağrı, deformiteler veya patolojik fraktürler eşlik ederse osteoporoz olarak isimlendirilir. ${ }^{12}$

Osteoporoz kemik yapımı ve yıkımı dengesinin bozularak, yıkımın arttığı bir tablodur. Kemik şeklinin bozulması ve yapının azalmasıyla karakterizedir ve kırığa yatkınlık söz konusudur. ${ }^{13}$

Senil veya postmenapoz dönemle ilgili olanına "primer osteoporoz" troid hipofonksiyonu, surrenal korteks hiperfonksiyonu gibi çeşitli hastalıklara veya ilaç kullanımı gibi etkenlere bağlı olanına "sekonder osteoporoz" denir. ${ }^{14}$ Orta yaş ve üstü kişileri etkiler, kadınlarda erkeklere oranla iki kat daha fazla rastlanır. ${ }^{14,15}$

Osteoporozda radyolojik olarak tüm kemiklerde kortikal tabaka incelmiş ve trabeküler yapı silikleşmiş ve kaybolmuştur. ${ }^{15}$
Reziduel kemik rezorbsiyonunu önlemek için uygulanan tedavilerin başında; östrojen takviyesi ve beslenme alışkanlıklarının düzenlenmesi gelmektedir. Günlük kalsiyum takviyesi kret rezorbsiyonunu yavaşlatır. ${ }^{16,17}$

Osteoporozlu hastalar belirli aralıklarla mutlaka takip edilmeli, hareketli protez kullanan hastaların alveol kretlerinde rezorbsiyon oluştuğunda hemen astarlama yapılmalıdır. ${ }^{2,18}$

Bifosfonatlar son zamanlarda osteoporoz tedavisinde artan bir rol kazanmışlardır. Bir aminobifosfat olan alendronat özellikle postmenopozal osteoporoz tedavisinde ve önlenmesinde yeni bir alternatif olarak İngiltere, Amerika Birleşik Devletleri ve diğer pek çok ülkede tanıtılmakta ve klinisyenler tarafından tercih edilmektedirler. Özellikle Paget hastalığının ve maligniteye bağlı hiperkalseminin tedavisinde en yaygın kullanılan bifosfonatlar etidronat, klodronat, alendronat ve pamidronatdır. Son yıllarda değişik bifosfonatların klinikte kullanılmasına karşın bunların kemik üzerindeki terapötik etkilerinde benzerlikler vardır. ${ }^{19}$

\section{Osteomalasi}

D vitamini eksikliğinde erişkinlerde görülen bir hastalıktır. Kemik kalsifikasyonundaki eksiklikle karakterizedir. Yürüme sırasında hastaların bel ve sakral bölgesinde ağrılar vardır. Zamanla bu bölgelerde deformasyon oluşur. Radyografide osteoporoz görülür. ${ }^{14,15}$

Hastalar belirli aralıklarla mutlaka takip edilmeli, alveol kretlerinde rezorbsiyon olduğunda hemen astarlama yapılmalıdır. ${ }^{2,18}$

\section{Recklinghausen Kemik Hastalığı}

Parat hormonun aşırı salgılanması durumunda ortaya çıkan bir hastalıktır. Kemiklerde deformasyonlar ve spontan kırıklar oluşabilmektedir. Basınç altında ağrı hissedilir. Radyolojik muayenede osteoporoz, kistler, kortikal atrofi ve havers kanallarında genişleme vardır. ${ }^{20}$

Yapılan protezler kesinlikle travmatik olmamalı, tam protezlerde bilateral balans sağlanmasına özen gösterilmeli, protezler sık sık kontrol edilmeli, endikasyon oluştuğunda astarlama veya kaide yenileme yapılmalıdır. ${ }^{2}$

\section{Amiloidoz}

Amiloidoz klinik belirtileri farklı boyutlarda görülen, vücudun değişik doku ve organlarındaki hücrelerin arasına patolojik homojen translüsent hiyalin birikmesi ile ortaya çıkan bir hastalıktır. En çok etkilenen organ dildir ve dilde makroglossi oluşabilmektedir. ${ }^{21}$ 
Dilin total protezlerde alt protezin tutuculuğu ve stabilitesini olumsuz etkilememesi için nötral alanın doğru bir şekilde tespitine ve cilalı yüzeylerin şekline azami dikkat edilmelidir. ${ }^{18}$

\section{HEMATOLOJİK HASTALIKLAR}

\section{Anemiler}

Eritrosit ve hemoglobinin normal değerinin altına çeşitli nedenlerle inmesine bağlı olarak ortaya çıkan klinik tabloya anemi adı verilir. Dolaşan kırmızı kan hücreleri kitlesinde azalma olarak da tanımlanır. Klinik bulgularında hasta aşırı yorgunluktan, halsizlikten, baş ağrısından, nefes darlığından şikayet eder. Bütün bu şikayetler kanın oksijen taşıma kapasitesindeki azalmadan kaynaklanmaktadır. ${ }^{22}$

Anemilerdeki oral bulgular olarak; ${ }^{23-27}$

1. Glossitis (dil üzerinde enflamasyon ve filiform papillalarda atrofi vardır. Dil kırmızı düz ve ağrılıdır),

2. Angular chelitis (ağız köşelerinde enflamasyon),

3. Mukozada lokal peteşiler ve eritemler sayılabilir.

Pernisioz anemi; kobalamin (vitamin B12 ve ekstrensek faktör) absorbsiyonun az olması nedeniyle ortaya çıkan çok sık rastlanmayan, daha çok yaşlı hastalarda görülen bir hastalıktır. ${ }^{22}$

Anemili hastalarda protez yaparken dikey boyutun doğru tespit edilmesine çok dikkat edilmelidir. Alçak alınan dikey boyut angular chelitis'i daha da artırabilir. Protezlerde travmaya sebep olabilecek tüm etkenler ortadan kaldırılmalı, cilalı yüzeyler iyice parlatılmalıdır. ${ }^{18}$

\section{KARDİOVASKÜLER HASTALIKLAR}

Bazı kardiovasküler hastalıklarda kullanılan ilaçlara bağlı olarak tükürük miktarı azalır. ${ }^{7,21}$

Tükürük miktarı azaldığında; ${ }^{27-30}$

1. Ağız kuruluğu oluşur, bu durum mukozayı mekanik travmalara karşı daha hassas kılar.

2. Normal temizleme faaliyeti yeterince yapılamadığından enfeksiyon riski artar.

3. Protezin tutuculuğu azalır.

Mekanik travmalardan korumak için; ${ }^{22}$

1. Protezle temasta olan mukozanın altındaki sivri kemik çıkıntıları yok edilmelidir.

2. Ölçü işleminde parsiyel protezlerde basınçlı, total protezlerde basınçsız ölçü alınmalı, protez kenarları hermetik olarak kapatılmalı ve uzun olmamalıdır.

3. Total protezlerde balanslı oklüzyon sağlanarak oklüzal kuvvetlerin alveol kemiğine eşit yayılması sağlanmalıdır.

4. Oklüzal kuvvetleri azaltıcı önlemler alınmalıdır. Örneğin:V-L boyutu dar olan dişler kullanılabilir veya yapay diş sayısı azaltılabilir.

5. Daimi kaide plağında çıkıntılar olmamalı, protez kenarları oval hazırlanmalıdır.

6. Protezin cilalı yüzeylerine dikkat edilmelidir.

7. Protezlerin doku yüzeyine yumuşak astar maddesi uygulanabilir.

Protezin tutuculuğunu artırmak için; 2,18,31

1. Tutuculuğu etkileyen diğer anatomik, fizyolojik ve mekanik etkenlerden yararlanılabilir.

2. Yapay tükürük kullanılabilir.

\section{HİSTIOSİTOSIS GRUBU HASTALIKLAR}

Çene kemiklerindeki rezorbsiyonla kendini belli eder. Alt çene üzerinde lokalize olan, kemik ağrılarından dolayı ölçü alırken ve protez yaparken dikkatli olunması gerekir. ${ }^{28}$

\section{Paget Hastalığı}

Kemiklerdeki boyutsal artış ile karakterizedir. Radyografide kemiğin bozulduğu ve atılmış pamuk (cotton wool) görünümünde olduğu görülebilir. Yeni kemik yapımı olan bölgelerdeki sinir-damar paketinin sıkışmasına bağlı olarak sağırlık körlük baş dönmesi, mental bozukluk, eklemlerde ağrı oluşabilir. Hastalar protezlerinin ağızlarına oturmamasından şikayet ederler. Tüberler bölgesindeki sürekli değişim nedeniyle protezlerin sık sık yenilenmesi gerekebilir. ${ }^{3,17}$

\section{BULAŞICI HASTALIKLAR}

\section{Hepatit, AIDS}

Bulaşıcı olan bu hastalıkların laboratuvar çalışanlarına bulaşma olasılığı vardır bu nedenle ölçüler ve modeller dezenfekte edilmelidir. ${ }^{32-34}$

\section{RADYOTERAPİ GÖREN HASTALAR}

$\mathrm{Bu}$ hastalarda osteoradyonekroz sıklıkla görülür. X ışınlarının mukozada sebep olduğu yaralar ve ülserasyonlar vardır. Ağızda dişler varsa kole bölgelerinde çürükler oluşur, sonra kırılmalar meydana gelir. ${ }^{20}$

Radyoterapi gören hastalarda total protez ya ülserasyonlar başlamadan veya iyileştikten sonra yapııı. Sebebi açıklanamayan bulantı refleksi ve nefes alma güçlüğü ile kendini gösteren solunum sistemi bozukluğu ölçü alma işlemi sırasında zorluk yaratabilir. Tükürükte görülen değişiklikler protezlerin retansiyonunu olumsuz etkiler. Tükürük akışının azalması tükürüğün protezi yağlayıcı etkisini azaltırken, aynı zamanda kuru olan mukoza aşırı hassas olur ve yara iyileşmesi gecikir.,28 Mukozal yaralanmalar, sekonder enfeksiyonlara, mukositis ve glossitise sebep olur.

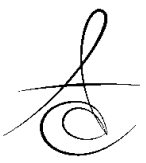


Protez yapılacağı zaman osteoradionekroza engel olmak için irritasyona sebep olabilecek bütün etkenler ortadan kaldırımalı, en az travmatik tekniklerle çalışarak protez yapılmalıdır. Protezlerin altına yağlayıc solüsyonlar sürülmeli, sodyum bikarbonatlı ağız gargaraları ve sakinleştirici ilaçlar tavsiye edilmeli, hastalar protezlerini sık sık çıkararak ağız mukozasını dinlendirmelidir. ${ }^{3,26}$

\section{NÖROLOJİK HASTALIKLAR}

\section{Myastenia Gravis}

İskelet kaslarının yorgunluğu ve güçsüzlüğü ile karakterize nöromuskuler kronik bir hastalıktır. Hastalık genellikle 20-30 yaş arasındaki kadınlarda ve 60-70 yaş arasındaki erkeklerde görülür. ${ }^{35}$ Asetilkolin salgısının azalmasına bağlı olarak kasların kontraksiyon yeteneği azalır ve sonuçta kas atrofisi gelişir. Çiğneme ve mimik kasları daha çok etkilenir. Konuşma ve yutmadaki güçlük ile birlikte hastada anlamsız bir yüz ifadesi gelişir. ${ }^{35,36}$

Tekrarlanan hareketler yorgunluk yapar, hasta dinlendiğinde düzelebilir. Bu nedenle hastalar sabahları kendilerini daha iyi hissederler akşamları ise yemek yiyebilmek bile bir sorun haline gelebilir. ${ }^{3}$

Protezler üzerindeki kas kontrolünün ortadan kalkması retansiyon bakımından olumsuzluk yarattığından, bu hastaların hareketli protez prognozu iyi değildir. ${ }^{31}$

\section{Parkinson hastalığı}

Alzheimer'dan sonra ikinci en yaygın, yaşa bağlı olarak görülen nörodejeneratif bir hastalıktır. ${ }^{37}$ Etiyolojisi bilinmediği için sorunu tamamen çözebilecek bir medikal tedavi yoktur. Beynin çeşitli bölgelerini etkileyen ilerleyici bir hastalıktır. Erkeklerde daha sık, kadınlarda ise çok ender görülür. Genellikle 60 yaşından sonra ortaya çıkar. Bu inatçı hastalığa yakalanan bireylerin tedavi sonrasında bile engellilik halleri devam etmektedir. Yürüme, yeme, ısırma, yutma zorluğu, hareketlerin düzgün olmaması, kasların rijiditesi ve titreme (tremor) en sık rastlanan bulgulardır. 3,38

Parkinson hastalığında diş hekimliği açısından ortaya çıkan sorunlar; ${ }^{37}$

- Perioral ve dil kaslarında titreme,

- Tükürük salgısında artış,

- Düzgün konuşmada bozukluk,

- Nöromüskülar kontrolde azlıktır.

Protez açısından önemine gelince; ${ }^{37}$

- Tükürük salgısındaki artış protezin retansiyonunun azalmasına neden olur.

- Hasta düzgün konuşamadığından dişlerin konumunun ve kaide plağının kalınlığının belirlenmesinde yardımcı olamaz.

- Çenelerden çeşitli kayıtların alınması zordur. Onun için sentrik kaydının statik bir pozisyon isteyen alçı gibi maddelerden değil stenç gibi termoplastik maddelerden seçilmesi uygundur. Yatay sentrik kapanış saptanırken, yapılan açma kapama hareketleri neticesinde sentrik ilişkinin değil, alışılmış sentrik oklüzyonun tespit edilmesi en ideal yaklaşımdır.

- Nöromüsküler kontrolleri zayıf olan hastaların yeni protezlerine adapte olmaları zordur. Bu hastalarda protez yapılacağı zaman ölçü yüzeyi ve dişlerin konumu hariç tüm cilalı yüzeyler daha önce kullanmış oldukları protezlerindeki gibi olmalıdır. ${ }^{2}$

Protez açısından olumsuzluk yaratan diğer nörolojik hastalıklar ise; yüz ve vücutta oluşan felçler, amyotrofik lateral skleroz, ilerleyici bulbar palsy, müsküler distrofiler ve myotonidir. ${ }^{4}$

\section{ROMATIZMAL HASTALIKLAR}

\section{Sjögren sendromu}

Egzokrin bezleri tutan otoimmün bir hastalıktır. İlk olarak tükürük ve gözyaşı bezlerini etkiler ve salgı azalması görülür. Sadece tükürük ve gözyaşı bezlerini etkilerse primer sjögren sendromu, romatoid artrit, sistemik lupus eritematozis, skleroderma gibi major hastalıklar da eklenirse sekonder sjögren sendromu olarak adlandırılır. ${ }^{39}$

Hastaların \%90'ını 50-60 yaş arasındaki kadınlar oluşturur. Çocuklarda, genç kadınlarda ve 65 yaş üstündeki kişilerde yaygın değildir. Tükürük ve gözyaşı eksikliği sonucu oluşan kuruluğa bağlı hastalıklar olabilir. Tüm mukozada hiperemik bir görüntü söz konusudur. ${ }^{23}$

Sjögren sendromlu hastalarda; ağız kuruluğu, stomatitis, mukoza hassasiyeti ve yanma ön planda olup, hareketli protez kullanma konusunda başa çıkılması zor bir tablo sergilerler. ${ }^{3}$ Sistemik anti enflamatuarlar ve diğer immunosüpresifler ile bu hasta grubunda başarılı sonuçlar alınamamış, göz preparatları gibi topikal anti enflamatuar ajanlar ve alfa-interferon gibi oral pastiller ile olumlu sonuçlar alınmıştır. ${ }^{32}$

\section{Sklerodermi}

Sistemik sklerozis (skleroderma), yaygın olmayan, fibrozis, inflamasyon ve vasküler değişiklikler ile karakterize bir bağ dokusu hastalığıdır. Etiyolojisi kesin olarak bilinmemektedir. Kadınlarda erkeklere oranla yedi kat daha fazladır ve genellikle 50 yaşın altındaki kişilerde görülür. ${ }^{40}$ 
Yaygın şiddetli deri kalınlaşması ve iç organ tutulumundan, sadece yüz ve ekstremitelerin distalindeki deri tutulumuna kadar olan şekillerinin yanında, deride kalınlaşmanın görülmediği tipleri içeren geniş bir klinik tablo gösterebilir. Diğer kollajen doku hastaIıkları ile bir arada bulunabilmektedir. ${ }^{41}$ Bazen dudak çevresi ve yüzde yani sadece lokal bir bölgede görülebilir. ${ }^{3}$

Dil frenilumunun kalınlaşması ve kısalması önemli bir bulgudur. Ağız tabanı ve dil kaslarının katııımı ile dil hareketleri kısıtlanması ile mikroglossi, mimik kaslarının hareketlerinin kıstlanması ile de mikrostomi oluşur. Böyle bir durumda tam protezlerde stabiliteyi sağlamak oldukça zordur. ${ }^{3}$

\section{BÜLLÖZ MUKOZA HASTALIKLARI}

Büllöz mukoza hastalıklarında epitelyal ayrışma söz konusudur ve epitel hücreleri arası bağları oluşturan desmosom dejenerasyonu ile karakterize otoimmün bir reaksiyon ile oluşmaktadır. Spontan olarak veya çok küçük bir travma ile epitel değişik dereceerde ayrilabilmektedir. Bu durum oluştuğunda hareketli protezlerin kullanımı oldukça zor olmaktadır. ${ }^{3}$

\section{Eroziv-atrofik-büllöz oral liken planus}

Liken planus aslında bir deri hastalığıdır, ağızda da belirtileri söz konusudur. Etyolojisi kesin olarak bilinmemektedir. ${ }^{42}$

Bu kronik inflamatuvar hastalık, en sık yanak mukozasının distal kısmında ve genellikle simetrik olarak, dil sırtında, daha seyrek olarak diş etinde ışın demeti şeklinde beyaz çizgiler halinde eritematöz tip küçük, beyaz papüller veya plaklar şeklinde görülür. Genellikle asemptomatiktir. ${ }^{43,44}$

Hareketli protez yapımı kontrendike değildir. Ancak protez en küçük bir travmaya bile sebep olmamalıdır. Hastalı̆ın eroziv dönemlerinde protezlerin kullanımı genellikle mümkün olmamaktadır. Hastaya bu dönemlerde protezini kullanmaması önerilebilir. ${ }^{3}$

Dental tedavilerinin planlanması sırasında sistemik hastalıkların ağız bulguları saptandığında, ağız ortamındaki rahatsızıkların giderilmesi için hastaya tedavi veya tavsiyelerde bulunmak ya da hastaları gerekli merkezlere yönlendirmek oldukça önemlidir.

\section{KAYNAKLAR}

1. Özcan B. Bruksizme eşlik eden miyofasyal ağrı sendromlu ve temporomandibular rahatsızlğı olan hastalarda oklüzal splint ve tens tedavilerinin klinik ve ağrı eşiği üzerine olan etkinliklerinin karşılaştırıması (Uzmanlık Tezi). İstanbul, 2005.

2. Çalıkkocaoğlu S. Dişsiz Hastaların Protetik Tedavisi. Klasik Tam Protezler. İstanbul, 1998: p. 20-9.

3. Sonis ST, Fazio RC, Fang L. Principales and Practice of Oral Medicine. 2nd edition. WB Saunders Co; Philedelphia 1995: p. 131- 62.

4. Bell GW, Large DM, Barclay SC. Oral health care in diabetes mellitus. SADJ. 2000;55:158-65; quiz 175. Review.

5. Walsh LJ, Cleveland DB, Gumming CG. Quantitative evaluation of Langerhans cells in median rhomboid glossitis. J Oral Pathol Med 1991; 21:28-33.

6. Carter LC. Median rhomboid glossitis: Review of a puzzling entity. Compendium 1990; 11:448-51.

7. Grushka M. Clinical features of burning mouth syndrome. Oral Surg Oral Med Oral Pathol 1997; 63:30-6.

8. Tourne $L P$, Fricton JR. Burning mounth syndrome. Critical review and proposed clinical management. Oral Surg Oral Med Oral Pathol 1992:74:158-67.

9. Cibirka RM, Nelson SK, Lefebvre Ca. Burning mouth syndrome: A review of etiologies. J Prosthet Dent 1997;78:93-7.

10. Sykes LM, Sukha A. Potential risk of serious oral infections in the diabetic patient: A clinical report . J Prosthet Dent 2001;86:569-73.

11. Renner RP, Boucher $\sqcup$, Kaufman HW.Osteoporosis in postmenopausal women. J Prosthet Dent J Prosthet Dent 1984;52:581-8.

12. Loza JC, Carpio LC, Dziak R. Osteoporosis and its relationship to oral bone loss. Curr Opin Periodontol 1996;3:27-33.

13. Nordin BE. The definition and diagnosis of osteoporosis. Calcif Tissue Int 1987;40:57-8.

14. Ortman LF, Hausmann E, Dunford RG. Skeletal osteopenia and residual ridge resorption. J Prosthet Dent 1989;61:321-5.

15. von Wowern N, Kollerup G. Symptomatic osteoporosis- a risk factor for residual ridge reduction of the jaws. J Prosthet Dent 1992; 67: 656-60.

16. Wical KE, Brussee P. Effect of a calcium and vitamin $\mathrm{D}$ supplement on alveolar ridge resorption in immediate denture patients. J Prosthet Dent 1979:41:4-9.

17. Faine MP. Dietary habits related to preservation of oral and skeletal bone mass in women. J Prosthet 
Dent 1995;73:65-72.

18. Berkey DB, Berg RG, Ettinger RL, Mersel A, Mann J. The old-old dental patient: the challenge of clinical decision-making. J Am Dent Assoc 1996;127;321-2.

19. Akarırmak Ü. Osteoporoz tedavisinde bifosfonatlar ve deneysel tedaviler. İstanbul Üniv Cerrahpaşa Tıp Fakültesi Sürekli Tıp Eğitimi Etkinlikleri Osteoporoz Sempozyumu 1999; 91-9.

20. Harorlı A, Yılmaz AB, Akgül HM. Diş Hekimliğinde Radyolojide Temel Kavramlar ve radyodiagnostik. Erzurum, Atatürk Üniv. Ofset tesisleri, 2001: p.35.

21. Cohen AS. Proteins of the systemic amyloidosis. Curr Opin Rheumatol 1994; 6: 55-67.

22. Brad WN, Douglas DD, Carl MA, Jerry EB. Oral and Maxillofacial Pathology. W.B. Saunders Co; Philedelphia 1995:p. 604-8.

23. Ünlü $M$, Onur Ö. Ağız hastalıklarının teşhis ve tedavisi. İstanbul, 2003: p. 47-267.

24. DeRossi SS, Raghavendra S. Anemia. Oral Surg Oral Med Oral Pathol Oral Radiol Endod 2003; 95; 131-41.

25. Olivieri NF. Treatment strategies for hemoglobin $E$ beta-thalassemia. Blood Rev 2012;26 Suppl 1:S2830. doi: $10.1016 / S 0268-960 X(12) 70009-7$.

26. Nunes C, Escudier M, Sanderson J. Disorders of the mouth. Medicine 2007; 35: 189-93.

27. Atkinson JC, Grisius M, Massey W. Salivary hypofunction and xerostomia: diagnosis and treatment. Dent Clin North Am. 2005;49:309-26.

28. Ghezzi M. ELISA,"Systemic diseases and their treatments in the elderly:impact on oral health",Journal of Public Health Dentistry 2000;60:290.

29. Dawes C, Edgar WM, O'Mullane DM. Factors influencing salivary flow rate and composition. In saliva and Oral Health. British Dental Association London 1996; 27-41.

30. Diaz-Arnold AM, Marek CA. The impact of saliva on patient care: A literature review. J Prosthet Dent 2002;88:337-43.

31. Özdemir AK. Hareketli Protezler (Kliniğe Hazırık). Sivas, 2002;p. 19-25.

32. Budtz-Jorgensen E. Oral mucosal lesions associated with wearing of removable denture. J Oral Pathol 1981;10:65-80.

33. Witzel AL, Pires Mde F, de Carli ML, Rabelo GD, Nunes TB, da Silveira FR. Candida albicans isolation from buccal mucosa of patients with HIV

wearing removable dental prostheses. Int J Prosthodont. 2012;25:127-31.

34. Badrian $\mathrm{H}$, Ghasemi E, Khalighinejad N, Hosseini N. The effect of three different disinfection materials on alginate impression by spray method. ISRN Dent. 2012;2012:695151. doi: 10.5402/2012/ 695151.

35. Yarom N, Barnea E, Nissan J, Gorsky M. Dental management of patients with myasthenia gravis: a literature review. Oral Surg Oral Med Oral Pathol Oral Radiol Endod 2005;100:158-63.

36. Schneider PE. Dental management of a child with severe myasthenia gravis. Spec Care Dentist 1983;3:266-70.

37. Allain $H$, Bentué-Ferrer $D$, Akwa $Y$. Diseasemodifying drugs and Parkinson's disease. Prog Neurobiol 2008;84:25-39.

38. Nakayama $Y$, Washio M, Mori M. Oral health conditions in patients with Parkinson's disease. J Epidemiol 2004;14:143-50.

39. Ship JA, Fox PC, Michalek JE, Cummins MJ, Richards AB. Treatment of primary Sjögren's syndrome with low-dose natural human interferonalpha administered by the oral mucosal route: a phase II clinical trial. IFN Protocol Study Group. J Interferon Cytokine Res 1999;19:943-51.

40. Jagger RG, Absi EG, Jeremiah HG, Sugar AW. Bilateral mandibular condylysis in a patient with systemic sclerosis. Dentomaxillo fac Radiol 2006;35:461-3.

41. Tülek N, Aydıntuğ O, Özoran K, Kınıklı G, Düzgün N, Duman M, Tokgöz G. Sklerodermanın erken klinik bulguları. Ankara Tıp Mecmuası (the journal of the faculty of medicine) 1994;47: 309-16.

42. Corrêa L, Frigerio ML, Sousa SC, Novelli MD.Oral lesions in elderly population: a biopsy survey using 2250 histopathological records. 2006;23:4854.

43. Dorey JL, Blasberg B, MacEntee MI, Conklin RJ. Oral mucosal disorders in denture wearers. J Prosthet Dent1985;53:210-3.

44. Altuğ HA, Şençimen M, Okçu KM. Oral liken planus: olgu sunumu. Gülhane Tıp Dergisi 2010;52:140-2

\section{Yazışma Adresi}

Prof. Dr. Zeynep YEŞİL DUYMUŞ

Recep Tayyip Erdoğan Üniversitesi

Diş Hekimliği Fakültesi

Protetik Diş Tedavisi Ana Bilim Dalı- Rize

E mail: zyesilz@hotmail.com 